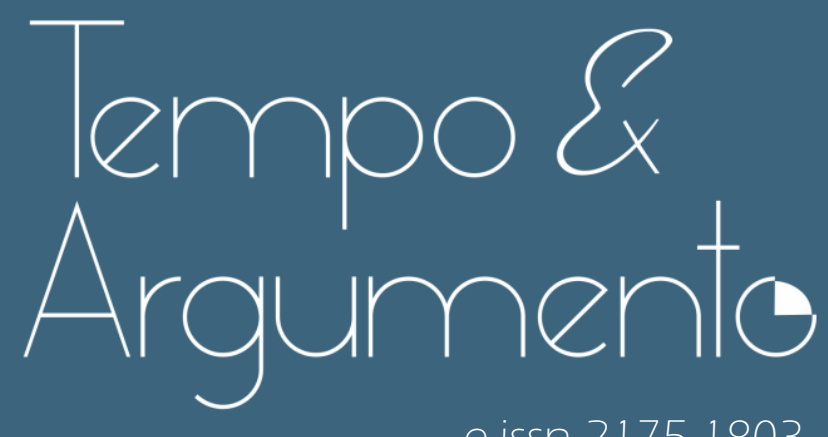

e-issn 2175-1803

Marie Marcks: a visualidade do político e o

Feminismo ilustrado na Alemanha ( 1963 - 2014)

- Vinícius Liebel

Doutor em Ciência Política pela Freie Universität Berlin (FUB - Alemanha).

Professor da Universidade Federal do Rio de Janeiro (UFRJ).

Rio de Janeiro, RJ - BRASIL

lattes.cnpq.br/6576515023904018

v.liebel@uol.com.br

(D) orcid.org/0000-0002-3188-6567

Para citar este artigo:

LIEBEL, Vinícius. Marie Marcks: a visualidade do político e o Feminismo ilustrado na Alemanha ( 1963 - 2014). Tempo e Argumento, Florianópolis, v. 12, n. 31 , e0 104, set./dez. 2020.

do) http://dx.doi.org/10.5965/2175180312312020e0 104

Recebido: 15/01/2020

Aprovado: 19/05/2020 


\title{
Marie Marcks: a visualidade do político e o Feminismo ilustrado na Alemanha (1963 - 2014)
}

\begin{abstract}
Resumo
Lutas políticas e sociais têm visualidade. Para além do cerimonial que, por vezes, envolve a política, toda ação que se desenvolve no campo do político é, também, uma questão visual. Charges e cartuns, partes inerentes e destacadas da imprensa escrita, revelam-se também, dessa forma, ações comunicativas visuais, e são percebidas como uma ação política específica, com importância e efeito no campo público, político e social da aparência (Arendt). Elas se tornam documentos de sua época e de um determinado grupo político-social e se mostram, elas mesmas, na forma de representação, atuantes nesse espaço do político. É considerando essas características das charges que o presente artigo levanta as charges da desenhista alemã Marie Marcks, considerada uma das principais vozes do feminismo alemão. Atuante a partir da década de 1960, seus desenhos, com enorme aceitação e entrada na grande mídia, abordam temas caros ao feminismo de forma direta, mesmo em tempos ainda resistentes a eles. Dividido em três partes, o artigo explora, em primeiro lugar, a conceitualização do campo público/político e sua visualidade, caracterizando o espaço no qual transitam as charges e sua especificidade. Segue-se uma breve biografia de Marie Marcks e a caracterização da conjuntura de sua atuação para, em seguida, baseando-se no método documentário de análise de imagens, efetuar uma análise de algumas de suas obras mais representativas, dando conta, assim, do aspecto historiográfico e técnico da atuação de Marcks.
\end{abstract}

Palavras-chave: Marie Marcks. Charges. Opinião pública. Política. Feminismo.

\section{Marie Marcks: the visuality of the political and the illustrated Feminism in Germany (1963 - 2014)}

\begin{abstract}
Political and social struggles are visual. Apart from the ceremonial acts that sometimes involves politics, every agency that is developed in the political arena is also a visual phenomenon. Cartoons, as inherent and prominent parts of the written press, are also visual communicative actions, and are perceived as specific political actions, with importance and effect on the public, political and social space of appearance (Arendt). They become documents of their time and of a particular social-political group and show themselves in the form of representation, acting in this space of the political. Considering these characteristics of cartoons, the work of German cartoonist Marie Marcks, considered one of the main voices of German feminism, is revisited on this paper. Active since the 1960s, her drawings are widely accepted, having entry in the mainstream media. They directly address themes dear to feminism, even in a time that is still resistant to them. Divided into three parts, the paper explores the conceptualization of the public / political space and its visuality, characterizing the space through which cartoons move as well as their specificity in the political space. It is followed by a brief biography of Marie Marcks and a description of the conjuncture of her performance so that, based on the documentary method, some of her most representative works are analysed, giving thus an account of the historiographical and technical background of Marcks' agency.
\end{abstract}

Keywords: Marie Marcks. Cartoons. Public opinion. Politics. Feminism. 


\section{Introdução}

Seus desenhos, para muitos hoje em dia, talvez sejam considerados um pouco ingênuos. Seu estilo, fortemente influenciado pelas publicações humorísticas francesas, como a Hari-Kiri, e especialmente pelo chargista Jean Bosc, são marcados pela simplicidade conjugada a uma sagacidade bastante característica, tomando como alvos preferenciais os homens de seu tempo. Mesmo assim, em seu período de maior produção, entre os anos 60 e 80, e ainda que reconhecida por sua atuação em favor do feminismo, nunca faltaram dedos para apontar para sua falta de engajamento político, para uma certa condescendência para com os homens em seus desenhos?'. Para esses, seu humor não era suficientemente violento, não era suficientemente humilhante evocando uma clássica afirmação de Bergson, segundo a qual o humor serviria à humilhação pública que, por sua vez, orientaria as correções necessárias à sociedade ("Se Harpagon nos visse rir de sua avareza, eu não the digo que se corrigiria, mas a mostraria menos, ou a mostraria de outro modo." (BERGSON, 2001, p. 13).). Contra as críticas e contra uma sociedade machista e conservadora, Marie Marcks fez o seu nome em um meio que, ainda hoje, é predominantemente masculino.

A atuação de Marcks na Alemanha Ocidental, a partir dos anos 1960, ganha uma projeção que, pode-se dizer, raras vezes mulheres haviam conseguido na imprensa até então. E ainda, se a atuação feminina na imprensa alemã cresce, tanto em número quanto em importância (ainda que, muitas vezes, incógnita) a partir de meados do século XIX (KLAUS; WISCHERMANN, 2013), Marcks representa um ponto totalmente novo no que se refere à atuação de chargistas na grande imprensa do país. Sua atuação profissional é responsável por inserir um olhar feminino e feminista na arena pública alemã, construindo uma visualidade própria - através de seu estilo, das temáticas trabalhadas, de suas opiniões transpassadas para o papel e através da própria materialidade que seu trabalho ganha ao ser publicado.

\footnotetext{
Männerfreundlich (amigável para com os homens) foi o adjetivo com o qual a própria Marcks se descreveu em entrevista de 2012, por ocasião de seu 90o aniversário, ao explicar as razões de nunca ter publicado na revista Emma, uma das principais revistas feministas da Alemanha, apesar de ter tentado fazê-lo ao menos uma vez (EICKHOFF, 2012).
} 
Neste artigo, a importância e as características da contribuição de Marcks ao espaço público da RFA serão sublinhadas, levando em consideração algumas reflexões de cunho teórico que guiarão a apresentação e análise de sua produção, particularmente aquela voltada aos questionamentos das estruturas e das ações de mulheres e homens naquele contexto. Tais reflexões se referem à constituição do espaço público, do campo do político e, em especial, à sua caracterização como um espaço de visualidade. Após essas considerações, segue-se uma breve biografia de Marie Marcks e a apresentação interpretativa de algumas de suas obras mais representativas, interpretações que serão guiadas pelas balizas do método documentário (BOHNSACK, 2007; 2009; LIEBEL, 2010; 2011; 2016; PRZYBORSKI, 2017).

\section{A Visualidade do Político}

$\mathrm{Na}$ teoria política arendtiana, dois pontos fundamentais se destacam na caracterização da ação política. O primeiro é que a ação política precisa ser pública, ela precisa ser aberta e coletiva. O nome que se dá ao espaço de realização para essas atividades é o campo do político, o lugar de experimentação da existência interpessoal, (Inzwischen). Para ela, a ação efetuada no campo do político tem como elemento central as pessoas, os atores que efetuam essa ação, sempre pensada em termos de pluralidade, e não de individualidade. Em Origens do Totalitarismo, a teórica argumenta que o Terror totalitário leva a um completo isolamento dos indivíduos, uma atomização social que cria um deserto no campo do político. O Terror, completa ela,

[...] como servo obediente do movimento natural ou histórico (e aqui ela trata das ideologias totalitárias), tem de eliminar do processo não apenas a liberdade em todo sentido específico, mas a própria fonte de liberdade que está no nascimento do homem e na sua capacidade de começar de novo. No cinturão de ferro do terror, que destrói a pluralidade dos homens e faz de todos aquele UM que invariavelmente agirá como se ele próprio fosse parte da corrente da história ou da natureza, encontrou-se um meio não apenas de libertar as forças históricas ou naturais, mas de imprimir-lhes uma velocidade que elas, por si mesmas, jamais atingiriam. (ARENDT, 1999, p. 518) 
Essa reflexão sobre a ação do Terror ilumina precisamente esse conceito de campo do político, uma vez que explicita a força usada para a quebra do plural, para o isolamento do indivíduo e para sua automatização nas massas. Utilizando o caso da Alemanha nazista para reflexão, fica evidente que o medo e a desconfiança corrompem o ambiente e eliminam esse espaço do fazer junto, da reflexão conjunta, e a ideologia totalitária cumpre assim um papel homogeneizador, desindividualizando as pessoas e transformando-as em massa. Desindividualizando, pois o indivíduo é aquele capaz de reflexão, da ação consciente em busca de e no exercício da liberdade, na composição conjunta de poder que gera a capacidade de ação coletiva.

Essa caracterização pública do campo do político está fortemente vinculada a uma imagem da polis grega, à Ágora democrática, tomada como o espaço do político, público, portanto, em contraposição à casa, o âmbito do privado. Mas mais do que isso, ela pressupõe alguma forma de contato material entre os agentes, pressupõe a criação de um espaço de trocas e de percepções mútuas que condiciona, rege e fomenta essa relação coletiva. Nesse campo do plural, onde se vê, ouve e sente o próximo, é que captamos informações e ideias que guiarão nossas reflexões, que respaldarão as conclusões que serão fruto de nossa consciência. Quanto menos modelos tivermos para a composição dessa consciência alargada, menor será nossa possibilidade e nossa capacidade de pensar a pluralidade, e, consequentemente, mais próxima da unidimensionalidade será a ação e a reflexão. A uniformidade das ações no campo público, no modelo da Gleichschaltung empreendida pelos nazistas, visava à supressão da intersubjetividade, pois em seu cenário ideal já não há subjetividade, posto que ela foi substituída pela objetividade. Já não existem dúvidas de como se portar, de como agir: tudo e todos são iguais, são os mesmos. Todos são aquele "um" que, na citação de Arendt, "invariavelmente agirá como se ele próprio fosse parte da corrente da história ou da natureza” (ARENDT, 1999, p. 518). Não existem opiniões, apenas a verdade da ideologia.

Esse estágio final, entretanto, nunca foi alcançado. A distopia de fundo orwelliano, na qual as relações humanas são completamente aniquiladas e o

\footnotetext{
Padronização ou alinhamento, no sentido de conformação das diferentes personalidades e atuações a um modelo específico e oferecido pelo regime e/ou pela ideologia.
} 
ambiente é completamente uniformizado em todas as esferas da vida, nunca se completou. Os motivos são apontados por Chantal Mouffe (2016), quando ela preconiza o caráter agonístico do campo do político. "O político nunca pode ser erradicado porque consegue extrair suas forças dos mais diversos empreendimentos humanos" (MOUFFE, 2016, p. 11). Aqui a reflexão se torna mais ampla. Para Mouffe (2014), o campo do político (em especial em uma democracia pluralista, como é o caso do ambiente onde Marie Marcks age) não é (apenas) o campo do consenso, mas principalmente o da disputa agonística (ou antagonística). Diferenças se tornam evidentes no contato com os demais indivíduos. É esse contato que caracteriza e cria o campo do político.

Daí decorre o segundo ponto fundamental da teoria da ação no campo do político: sua visualidade. Ao concebermos a relação intersubjetiva como um primado do político, a existência do outro ${ }^{3}$ se torna uma pré-condição para a concepção da própria arena pública, de um campo de experiências que se paute pela troca, pela reflexão, pela ação conjunta e, também, pela confrontação e pela contraposição. Essa existência é percebida em forma de imagem, fornecendo, em primeiro lugar, as coordenadas pelas quais o indivíduo irá agir no campo do real, dando provas da pluralidade mais básica no mundo, aquela da aparência, e, em segundo lugar, as representações que servirão de base para o pensar, o refletir e o julgar. Em outras palavras, "o político é visto, ouvido, sentido e apreendido através de uma forma sensível de ser, produzindo julgamento e imaginação como funções da sensibilidade" (SJÖHOLM, 2015, p. X). A própria produção de identidades, sejam elas individuais ou coletivas, se pauta largamente na aparência, tendo na exterioridade constituinte (STATEN, 1984) uma de suas características mais marcantes. Modelos e contramodelos se tornam signos que são apropriados e interpretados de formas distintas de acordo com o contexto ou com a história de cada um. Em suma, é na relação entre a exterioridade e a consciência que essas imagens transitam, carregando consigo interpretações e significados específicos.

\footnotetext{
${ }^{3} \mathrm{Na}$ formulação de Arendt, "ser e aparecer coincidem [...]. Nada e ninguém existe neste mundo cujo próprio ser não pressuponha um espectador. Em outras palavras, nada do que é, à medida que aparece, existe no singular; tudo que é, é próprio para ser percebido por alguém." (ARENDT, 2012, p. 35).
} 
Na terminologia arendtiana, as ações do espírito (pensar, querer, julgar) que se desenrolam sobre determinada pessoa, tema ou objeto, entretanto, são sempre baseadas ou influenciadas pelo mundo sensório, pelas experiências dos sentidos, pelo acúmulo de informações que armazenamos sobre o objeto de reflexão a partir do exterior. Esse processo é o mesmo, ou ao menos bastante similar, àquele de formações de conceitos e abstrações em nossa consciência, como, por exemplo, os conceitos de "democracia" ou de "brasileiro". Nosso depositório de imagens e as noções providas do senso comum nos ajudam a formar uma imagem desses conceitos. As informações utilizadas nesse processo, entretanto, são sensórias. Voltamos, assim, à questão da exterioridade constituinte, do papel do mundo sensório na constituição do eu, da identidade individual e coletiva. E encontramos a especificidade própria das charges, que agem no campo do político como elementos visuais plenos de significados, propondo narrativas, discussões e conceituações. Artistas como Marie Marcks exponencializam sua ação através da difusão midiática de sua obra, através da qual atuam, efetivamente, no campo visual do político.

Tais questões, como já colocado, movem-nos no mundo das aparências, no campo do político, no qual essas imagens (reais e mentais) entram em contato com o campo das sensibilidades. Nesse espaço, em que o político e a aparência se tocam, é que percebemos que estética e política compartilham aquilo de mais básico, mas também de mais específico que possuem, ou seja, aquilo que se dá aos sentidos e que carrega consigo um sentido próprio, conjuntural, que é, ao mesmo tempo, comum a toda sociedade, mas também restritivo em sua representação dos atores e elementos autorizados a exercê-lo. Nesse sentido, a expressão pictórica não escrita - ou seja, as imagens em geral - ganha uma especificidade própria ao ser dotada de uma eficácia quase instantânea sobre o receptor. As sensibilidades próprias do campo do político, as violências e as paixões ganham em potencialidade nas representações visuais (artes cênicas, cinema, pintura, quadrinhos e, o que nos interessa particularmente, charges), garantindo ao campo da cultura o papel de espaço privilegiado para o estudo e observação do objeto político, tanto na esfera da dominação quanto nas esferas da cooperação, da confrontação ou da resistência. Trata-se, como explica Rancière, de 
um recorte dos tempos e dos espaços, do visível e do invisível, da palavra e do ruído que define ao mesmo tempo o lugar e o que está em jogo na política como forma de experiência. A política ocupa-se do que se vê e do que se pode dizer sobre o que é visto, de quem tem competência para ver e qualidade para dizer, das propriedades do espaço e dos possíveis do tempo. (RANCIĖRE, 2000, p. 13-14)

Essas considerações corroboram a percepção arendtiana de um espaço das aparências que se caracteriza também como espaço público, e destaca a característica sensória e emocional desse lugar. "Certamente, o discurso em termos de falas, opiniões, trocas de sentidos, etc., é um aspecto inalienável da publicidade. Mas os exteriores sensíveis em forma de formas, sons, corpos vivos, movimento, etc. também o são. Estórias, música, espetáculos visuais, tudo isso contribui para a esfera pública" (SJÖHOLM, 2015, p. 3). Mesmo a imagem de capa de um jornal exposto numa banca irá contribuir para esse espaço das aparências. A pluralidade, elemento essencial da caracterização do político em Arendt, se torna não apenas a multidão de indivíduos ou atores, mas também a variedade de aspectos e aparências. Toda iconografia acaba ganhando um nível de sentido conjuntural que faz dela partícipe do campo do político, como ações de atores, como expressões políticas. O quadro, o retrato, ao se tornar público, ganha peso político; a performatividade dos atores retratados ou dos artistas em uma encenação ou em uma peça de teatro se torna constituinte do campo do político. Assim como a música ouvida pode se tornar também som do político. Reflexões despertadas, sensações e emoções trazidas à tona por essas expressões se tornam constituintes desse processo, desse espaço público do político.

As implicações historiográficas dessa reflexão apontam para a necessidade de compreender a emergência dessas subjetividades e seus desdobramentos na história. Evidencia-se a necessidade de apreender o como da história: como uma linha estética se torna relevante em determinado contexto, como o julgamento e/ou determinado senso comum se formam, como uma imagem e um sentimento se conformam historicamente. O caso das charges, como tratado aqui através do exemplo de Marie Marcks, torna-se ainda mais complexo, uma vez que se trata de representações de implicações políticas que seguem estratégias discursivas e performativas específicas, mas que dão uma visualidade a encenações e caracterizações humorísticas, parcialmente 
baseadas na realidade. Em outras palavras, as charges dão uma existência no real para ideias hiperbólicas e imagens metafóricas que provêm da imaginação e reflexão do(a) chargista, dando assim a elas uma entrada na arena pública e intervindo no mercado de bens de significado (ANSART, 1978, p. 85).

É possível mesmo pensarmos em que sentido as charges, ao serem publicadas e publicizadas, não se tornam elas mesmas agentes, portadoras que são de uma visualidade, de uma performatividade, de um discurso. Sua atuação obedece à lógica de sua distribuição, compondo um espaço demarcado por sua presença, uma comunidade imaginada (no sentido de ANDERSON, 2006), ou melhor, uma comunidade de sentido que entrará em contato com a imagem, compreenderá sua mensagem e, por vezes, concordará com seu conteúdo. Sua ressonância será tanto maior quanto forem os aspectos ideológicos expressos em seu discurso que encontrarem como alvo ${ }^{4}$ receptivo seus leitores. Considerando os aspectos ideológicos do mercado editorial e jornalístico, ao qual as charges estão intimamente ligadas, é seguro dizer que essa comunidade de sentido se conforma à distribuição e vendagem do jornal ou da revista onde ela é publicada, tendo assim seu discurso uma segurança prévia de entendimento e grandes chances de aceitação. Na imagem maior da arena pública, as charges operam em busca da sedimentação de ideias em seu público-alvo e da conquista de novos adeptos, da propagação de discursos e julgamentos. Ao se dar a aparecer, ela opera como uma ponte, um aglutinador de atores (seus observadores/leitores) no campo do político, sendo parte da constituição de seu espaço intersubjetivo de experiências. Ela cumpre, ainda, um papel de difusora de valores, de práticas, de ideias e críticas que ganham entrada na arena pública através do filtro do humor político-social das charges.

As charges de Marie Marcks, em particular aquelas que se ocupam da crítica à sociedade patriarcal, machista e conservadora, e que são objeto deste artigo, servem, assim, à constituição de um campo visual do político, apresentando ideias em seu aspecto pictórico e auxiliando na remodelação das bases da sociedade através dos valores e das críticas apresentadas em seus

\footnotetext{
4 Para uma tipologia dos alvos das mensagens das charges, ver: LIEBEL, Vinicius. Charges. In: RODRIGUES, Rogério (org.). Possibilidades de pesquisa em história. São Paulo: Contexto, 2017. p. 83-114.
} 
desenhos. Sua entrada (tardia) em cena no campo público alemão ainda carregou consigo toda a vivência e a experiência da história alemã da primeira metade do século XX. Sua biografia está, portanto, fundamentalmente relacionada com as alterações da própria arena pública alemã no século passado.

\section{Marie Marcks - um entreposto geracional}

Nascida em Berlim, no ano de 1922, Marie Marcks vivenciou praticamente todo o drama alemão do século XX. O fim da Primeira Guerra, em 1918, foi seguido de uma revolução comunista que tentou implantar uma república de conselhos no país. Abafada pela polícia e pelos Freikorps, a Revolução Alemã tomou seu espaço no imaginário alemão do entreguerras como um conflito fratricida que expunha o extremismo da esquerda, sendo o evento assimilado por parcela da população como parte de uma grande conspiração pela derrota alemã na guerra, conspiração essa que envolveria não só os comunistas, mas também os plutocratas e os judeus. A República de Weimar, na qual Marcks viveu sua infância, tem sua arena pública aberta, uma imprensa completamente livre e desregulada, mas também o espaço do político marcado por um alto grau de moralização e suspeição, um gradual estreitamento do debate e a ascensão de uma cultura de exceção, na qual os indivíduos passam cada vez mais a rifar os valores democráticos em favor de um autoritarismo centralizado e que combatesse aqueles que seriam eleitos “inimigos”, na clássica distinção feita por Carl Schmitt (2008).

Aos 10 anos, ela viu a ascensão de Hitler ao poder e chegou à idade adulta em meio a uma ditadura totalitária e à guerra. Teve a oportunidade, nesse período, de iniciar sua educação superior, frequentando a Escola de Arte (Kunstschule) de Berlim. Filha de uma professora e de um arquiteto, o Terceiro Reich não foi um período de penúria ou de medo para ela. Em uma entrevista ao Frankfurter Allgemeine em 2013, Marie Marcks conseguia lembrar de momentos felizes no período. Quando questionada qual fora a maior aventura de sua infância, ela respondeu: "Os Jogos Olímpicos de 1936. Todas as crianças loiras e de olhos azuis, como minha irmã e eu, ficamos três meses fora da escola para praticar uma coreografia complexa no campo olímpico e demonstrar ao mundo 
como as crianças alemãs são saudáveis e bonitas." (OLYMPIA..., 2013). Marcks estudou ainda Arquitetura durante a guerra, dividindo-se entre Berlim e Stuttgart. Ao final do conflito, escolheu viver em Heidelberg, onde sua reputação como artista independente foi estabelecida lentamente.

Foi de Heidelberg, na zona de ocupação norte-americana, que Marie Marcks desenvolveu seu estilo, sua visão de mundo e criou sua família. Foi de lá que ela viu sua cidade natal ser dividida e uma ditadura se formar no lado oriental. Viu as lutas ideológicas que tomaram o país, as lutas de memória que inundaram o campo público nos anos 60, bem como os confrontos os anos 70 , que tiveram na milícia de extrema-esquerda Rote Armee Fraktion (RAF) sua expressão máxima. Para Marcks, as ideologias tendem ao autoritarismo, a uma postura antidemocrática, e por isso mesmo acabavam, em seus extremos, se assemelhando (Figura 1).

Figura 1: MARCKS, Marie. Aus Marx mach Hitler (De Marx faz-se Hitler).

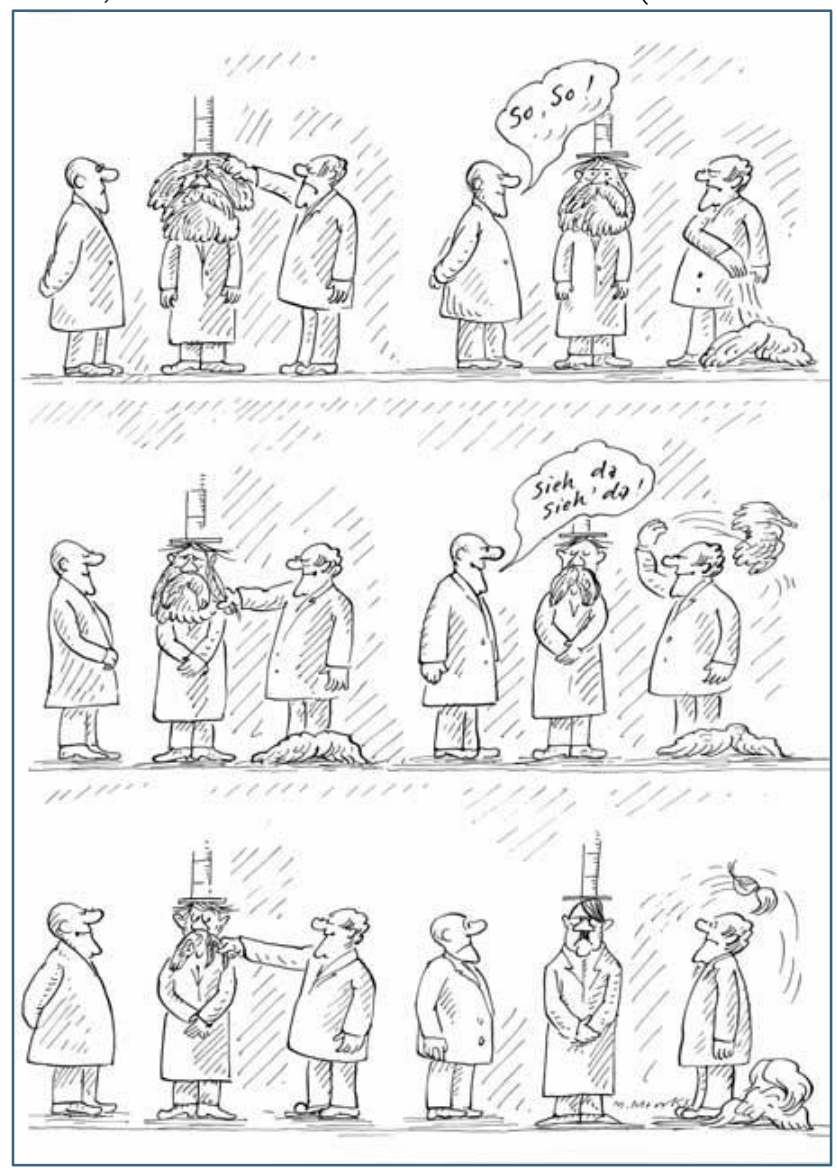

Fonte: LAMPRECHT, Rolf. Hundert Mal Bürgerrecht. Mannheim: Bibliog. Institut, 1979. Disponível em: http://marie-marcks.de/galerie/galerie-detail/innenpolitik/603/aus-marx-mach-hitler. 
Esse período, entre 1960 e 1980, foi o tempo de descoberta e de maturação de Marcks. Apesar de ter começado tarde quando comparada a outros chargistas (ela já se encontrava na casa dos 40), Marie trazia consigo experiências das quais os mais jovens não compartilhavam, como a guerra, o nazismo e a criação solitária de cinco filhos. Ao mesmo tempo, vivenciava um período de transformação e questionamento das gerações mais jovens. Ela se tornava assim um membro ativo, uma comentadora de seu contexto, valorizada por sua perspicácia, por sua inteligência e alinhada com as mudanças que os anos 60 traziam. A primeira publicação que acolheu as charges de Marcks, ainda em 1963, foi a Atomzeitalter, revista de comentários políticos e sociais editada em Frankfurt. Ao fim da década, ela já contava entre os grandes comentadores da imprensa alemã ocidental, e seus desenhos podiam ser vistos nas principais publicações do país, como a revista Der Spiegel e o jornal Süddeutsche Zeitung, ambos de abrangência nacional. O süddeutsche Zeitung conheceu, entre a metade da década de 1960 e a metade da de 1970, um crescimento sensível de sua circulação, alcançando 300.000 exemplares diários no ano de 1976. Já a revista Der Spiegel, no mesmo período, teve sua circulação semanal girando entre 900.000 e 960.000, o que demonstra a abrangência do público que entrava em contato com a obra de Marcks. Entre a denúncia da escalada atômica na Guerra Fria, das idiossincrasias da política nacional alemã e da permanência de estruturas e mentalidades autoritárias na sociedade alemã, os espaços da mulher e as relações de gênero vão ganhando visibilidade nos traços de Marcks. Apesar de não fazer parte da geração de 68, de não participar de seus movimentos e de suas ações, ela leva a vivência das mulheres alemãs às páginas dos principais meios de comunicação do país - e denuncia, assim, a condição subalterna da mulher naquela sociedade. Nas páginas da Spiegel e do $S Z$, em especial, o campo do político se alarga para Marcks, abrange uma grande parcela da população que estabelece uma relação visual e emocional com tais posicionamentos políticos, ressoando as proposições de Rancière que apresentamos acima.

Marcks é vista como uma figura sui generis no campo feminista alemão, uma espécie de elo entre o engajamento das sufragistas na Europa dos anos 
1910-20 e das feministas de segunda onda dos anos 1960. E como tal, podia ser vista com desconfiança por sua própria geração, e também pela nova. Sua geração vê a participação na arena pública com certo receio, marcada que fora pela política nazista. Já as feministas dos anos 60 tendiam a ver com certo desprezo, tanto a geração das sufragistas quanto a geração de Marcks. Os motivos para isso estavam claros para um dos nomes mais relevantes do movimento feminista. Germaine Greer, uma das principais vozes feministas do pós-guerra, aponta para uma diferença substancial entre as gerações: para ela, as sufragistas foram reformistas que lutaram por "profissões que declinaram de seguir, liberdades parlamentares que declinaram de exercer, academias que usaram cada vez mais como estabelecimentos onde podiam obter graduações enquanto esperavam o casamento." (GREER, 1971, 13). Em suma, lutaram por reformas que ajudaram no curso da história das mulheres e possibilitaram a vida de exceções que ousavam adentrar o mundo masculino, mas não eram revolucionárias.

$\mathrm{Na}$ afirmação de Greer existe um pouco de necessidade de demarcação da nova onda feminista, uma necessidade de se autoafirmar e de declarar ao mundo que ela seria mais forte, mais incisiva e mais duradoura. Mas, apesar disso, o ímpeto por mudanças realmente parece relaxar após a Primeira Guerra Mundial. Como Ute Frevert (1997) descreve em seu texto sobre a mulher na Alemanha, na geração seguinte parece haver um acomodamento das mulheres, e a "existência de um movimento de mulheres parecia irrelevante para muitas jovens que já haviam crescido sob a cláusula da igualdade constitucional." (FREVERT, 1997, p. 201). Uma acomodação que abriu espaço e alguma justificativa para movimentos conservadores de direita pregarem políticas reacionárias nesse campo - e não sem algum apoio de mulheres. O estudo de Wendy Lower (2014) demonstra como a geração seguinte tende a perceber como "vantagens" as políticas de (re)domesticação feminina, e como algumas carreiras, tidas como tipicamente femininas, davam oportunidade para alemãs servirem sua pátria, em especial nos territórios ocupados, ou para arrumarem um casamento. A exclusão das mulheres de qualquer posição de decisão, em particular na política, em que a elas não era sequer permitido se filiarem ao partido nazista, garante que 
medidas conservadoras e retrógradas sejam implementadas. Às mulheres era permitida uma participação reduzida no campo da política, mas, defendiam, essencial: no papel de secretárias. Esse era o retrato da geração de Marcks, uma geração que se encontra entre duas outras, marcadas pelas lutas das mulheres por seus direitos.

Mas assim como a onda feminista arrefece no entreguerras, ela retorna com força no pós-Segunda Guerra. Essa nova onda vem acompanhada de progressos nos campos social, científico e jurídico. O conflito mundial trouxe para o primeiro plano uma disposição mais aberta, principalmente na Europa Ocidental, com o fim das ditaduras autoritárias e conservadoras, e, aliado aos avanços, criou um ambiente propício às reflexões de gênero e do espaço da mulher na sociedade.

Ainda mais que as ciências destruíram alguns preconceitos e aboliram fronteiras até então intransponíveis. A definição da virilidade e da feminilidade se vê complexa demais para a biologia e a medicina, no momento mesmo que se enfraquecem as instituições que asfixiam mais às mulheres que aos homens, em particular o casamento e as grandes igrejas autoritárias. Não é surpresa que seja nessa confluência do científico e do sagrado, das práticas sociais conservadoras e da necessidade de evolução, que se situam (alguns d)os principais problemas atuais. (MUCHEMBLED, 2013, p. 232)

A Filosofia, a Psicologia e a Sociologia se abrem assim para reflexões mais subjetivas, em torno da condição do ser mulher, de sua participação política e de seu espaço na sociedade. As identidades são colocadas em xeque, e o feminismo conhece uma confluência com outros campos de reflexão, como a questão racial, da guerra e de classes. Nesse período, surgem questionamentos que ainda hoje movem reflexões, e apenas muito vagarosamente as questões de gênero vão deixar de ser questões binárias (ou seja, referentes apenas à contraposição homem-mulher). A grande maioria das pensadoras feministas do período do pósguerra vai se centrar na questão identitária feminina, visando promover um deslocamento da imagem da mulher frente àquela do homem de então. A revolução por elas intentada não estava apenas na descoberta de si, mas no uso dessa descoberta para alterar completamente a estrutura de sociabilidade, as relações diversas que envolvem as mulheres e thes impõem a subjugação. 
Marie Marcks se apresenta nesse contexto com suas charges. A temática que a lança ao campo do feminismo é justamente essa relação binária, a contraposição de um mundo masculino e sua abertura ao olhar e às práticas femininas. No pincel de Marcks esse debate ganha projeção, visualidade e reconhecimento na Alemanha Ocidental, deixando de ser um tema ligado estritamente a uma militância feminista e entrando na vida e nos lares da população alemã. Em outras palavras, a questão feminista ganha projeção pelo alargamento de um espaço de experiências, de uma comunidade de sentido, popularizando a questão feminista no país ao ultrapassar as fronteiras sociais e ideológicas. Ela influencia o campo do político com a visualidade e a discursividade de seus desenhos, participando, a seu modo, do fazer-junto que caracteriza o vínculo da ação e do discurso no campo do político de acordo com Hannah Arendt (2005).

As charges de Marcks eram populares e aceitas em veículos da grande mídia, e ainda que vistas como pouco incisivas pelas feministas, levam suas questões a novos públicos e alargam sua recepção e reflexão. Sua relevância e grande projeção, entretanto, talvez resida justamente em seu não alinhamento político, no fato de suas charges serem diretas, mas um tanto condescendentes para com os homens, como já colocado pela própria chargista. Ao desenhar para a grande mídia e estando envolvida na grande onda crítica e feminista de 1968, ainda que não militasse em organizações feministas, Marcks talvez tenha encontrado uma conivência maior, uma aceitação facilitada para suas charges e as críticas e valores que elas ensejavam. Fato é que seus desenhos se tornaram uma referência no país, e os temas do feminismo e das relações de gênero tiveram em suas charges e cartuns uma ancoragem visual que ressoa ainda hoje.

\section{Marie Marcks - O debate visual}

Na condição de chargista e de comentarista da sociedade alemã ocidental, Marcks consegue levar a mensagem feminista a um campo que, virtualmente, atinge todo o país, com sua obra amplamente aceita e bem-recebida. Nesse papel de amplificadora, a berlinense lançou mão de um estilo próprio, focando em temáticas próximas a ela e utilizando estratégias visuais-discursivas que aperfeiçoavam e refinavam sua posição no debate público. 
Para fins de análise, são trazidas duas charges produzidas por Marcks em momentos diferentes de sua longeva carreira, imagens que se diferenciam não apenas em termos de contexto, mas também de temática e de estratégia discursiva. O pano de fundo, no entanto, liga ambas ao inserirem pautas feministas nas duas representações.

Figura 02: MARCKS, Marie. Der pluralistische Charakter unserer Bildungsstruktur muss erhalten bleiben! (O caráter pluralista de nossa estrutura educacional precisa ser mantido!). 1975.

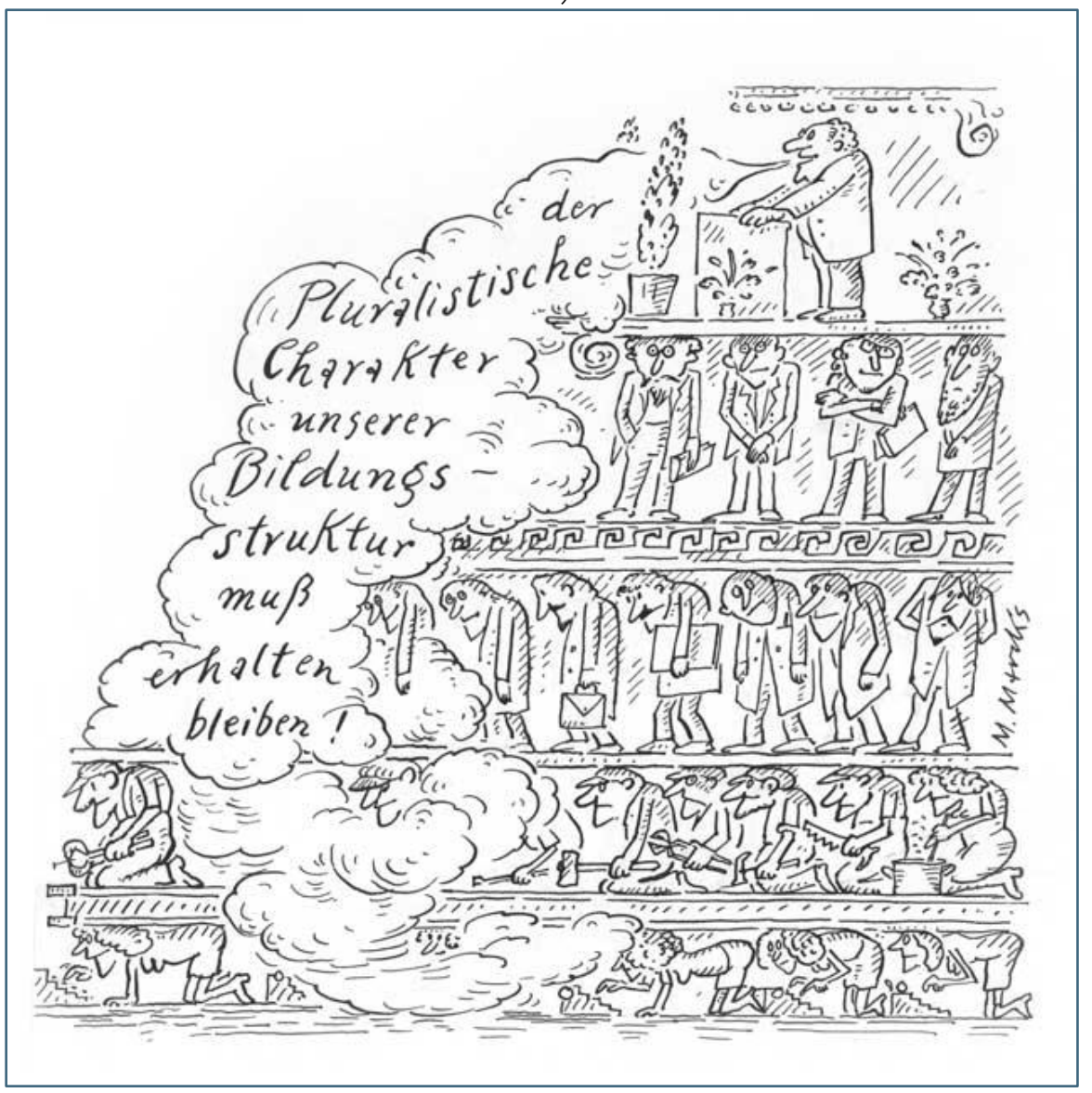

Fonte: Süddeutsche Zeitung, [München], 1975. Disponível em: http://mariemarcks.de/galerie/galerie-detail/jugend/44/der-pluralistische-charakter-unsererbildungsstruktur. Acesso em: 06 jan. 2020.

Na imagem acima (Figura 02), a visão de Marcks sobre a estrutura educacional alemã deixa claros os espaços que as mulheres nela (não) ocupavam. A estrutura, em formato piramidal (Figura 02a), mostra uma divisão estamental da sociedade alemã, assim como sua relação com a educação. Produzida em 1975, a imagem reflete ainda os debates levantados na década anterior, quando todo o sistema educacional e, principalmente, o lugar da 
universidade na sociedade foram colocados em xeque pelas manifestações estudantis de 1967-9. Entre as principais reivindicações dos estudantes contavam a reformulação do sistema educacional, sua expansão para diferentes camadas da sociedade e a formulação de currículos disciplinares mais úteis e próximos à realidade dos estudantes, além do rompimento com a estrutura autoritária que predominava na educação alemã. Em 1969, o partido socialdemocrata (SPD) ascende na política nacional e inicia uma reforma no sistema, que eleva o número de estudantes nas escolas e universidades, mas não vai ao encontro das demais demandas estudantis. A ironia que a charge de Marcks aponta corrobora essas reivindicações.

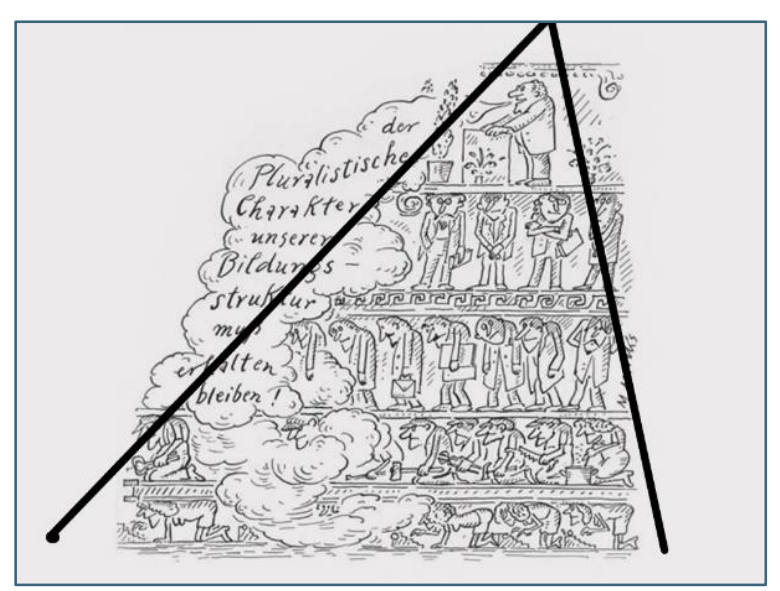

$02 \mathrm{a}$

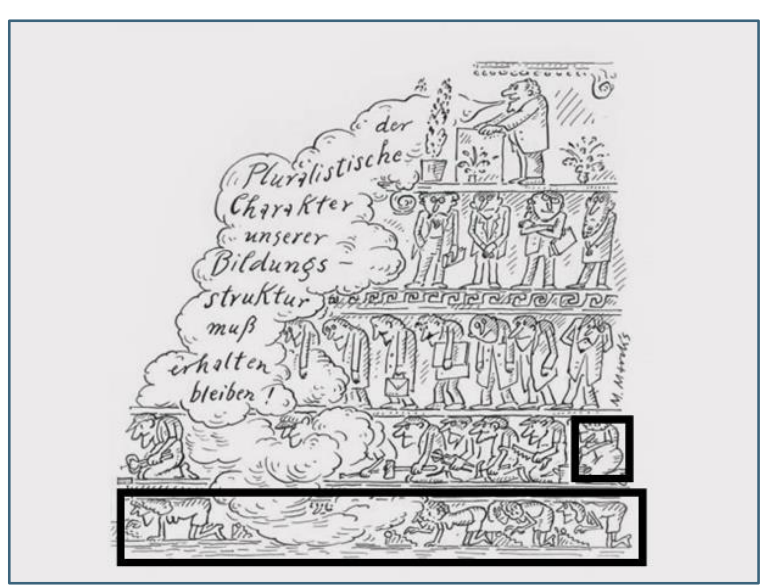

$\mathrm{O} 2 \mathrm{~b}$

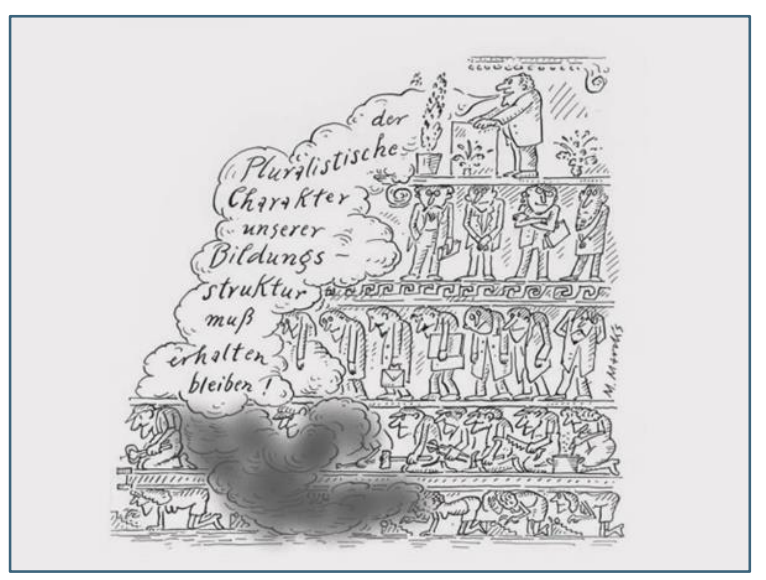

O2c

Ao discurso do político/acadêmico localizado no topo da pirâmide $(O$ caráter pluralista de nossa estrutura educacional precisa ser mantido!), contrapõe-se a visão de uma estrutura estagnada, na qual apenas o elemento 
superior parece satisfeito. Mais do que isso, os universitários, no segundo estamento, transparecem aborrecimento e os técnicos/profissionais liberais no terceiro nível da pirâmide demonstram apatia e desinteresse. Abaixo desses, na base da pirâmide, os trabalhadores parecem indiferentes. Mas na representação de Marcks, quem se encontra na base primária do sistema são as mulheres (Figura 02b), no trabalho doméstico, de “apoio” e de secretária. Por conta de sua situação subalterna, por estar "longe" do topo da pirâmide, o discurso proposto pelo topo mal chega a ser ouvido na base, onde os trabalhadores e as mulheres se encontram, fazendo com que o balão de diálogo que atravessa a imagem chegue já vazio em seu espaço, como demarcado na figura 02c pelo efeito esfumaçado. A questão que se evidencia nesse detalhe é: "para quem fala o elemento no topo da pirâmide?" Se o discurso mal chega nos trabalhadores e não chega, de forma alguma, nas mulheres, se a ação não se volta à emancipação, que tipo de campo do político, que formas de ação (ARENDT, 2005) podem ser esperadas das mulheres? É na produção de um campo que apresenta a questão e certa visualidade às mulheres que a imagem-mensagem de Marcks se localiza.

Existe, nessa construção imagética proposta por Marcks, uma clara referência à estratificação da sociedade que é demarcada, a um só tempo, pelo acesso à educação e a seus benefícios, pela posição econômico-social dos indivíduos e, finalmente, pelo gênero, estando a mulher na base da pirâmide como mão de obra sub ou não assalariada. A expressão performativa dos elementos representados também aponta para a maior subjugação do sistema sobre as mulheres: enquanto os elementos das três primeiras castas conseguem se manter em pé, os da quarta precisam ficar de joelhos e a base, formada unicamente por mulheres, se encontra totalmente pressionada. O tema da mulher no campo de trabalho assalariado - e fora dele, na invisibilidade do trabalho doméstico não assalariado - permanece uma constante na obra da chargista, e é, em praticamente todas as charges que envolvem o tema das relações de gênero, o pano de fundo de seus discursos. Publicada em um dos principais jornais do país, o Süddeutsche Zeitung, sediado em Munique e com abrangência nacional, a mensagem ganha espectadores e amplia a comunidade de sentido que a apreende, não só entre o público masculino, mas também entre 
o feminino. O homem é instado a reconhecer seus privilégios e a mulher é chamada a tomar consciência de sua posição. A questão bergsoniana do humor, do componente de humilhação que ele carrega consigo, atinge aqui ambos os lados.

Mas ainda que indique uma busca pela conscientização das mulheres, não há um elemento revolucionário na charge, uma chamada à ação. Talvez aqui resida a resistência de feministas militantes à obra de Marie Marcks. A sociedade é mostrada "como ela é", a mulher é representada em posição subalterna, mas também não há qualquer esboço de reação a essa situação. Essa situação se mostra ainda mais explícita na imagem seguinte, publicada em 1981, na revista Stern.

Figura 03: MARCKS, Marie. Es muss endlich schluss sein mit der Diskriminierung der Frau! (É preciso acabar de uma vez por todas com a discriminação da mulher!), 1981.

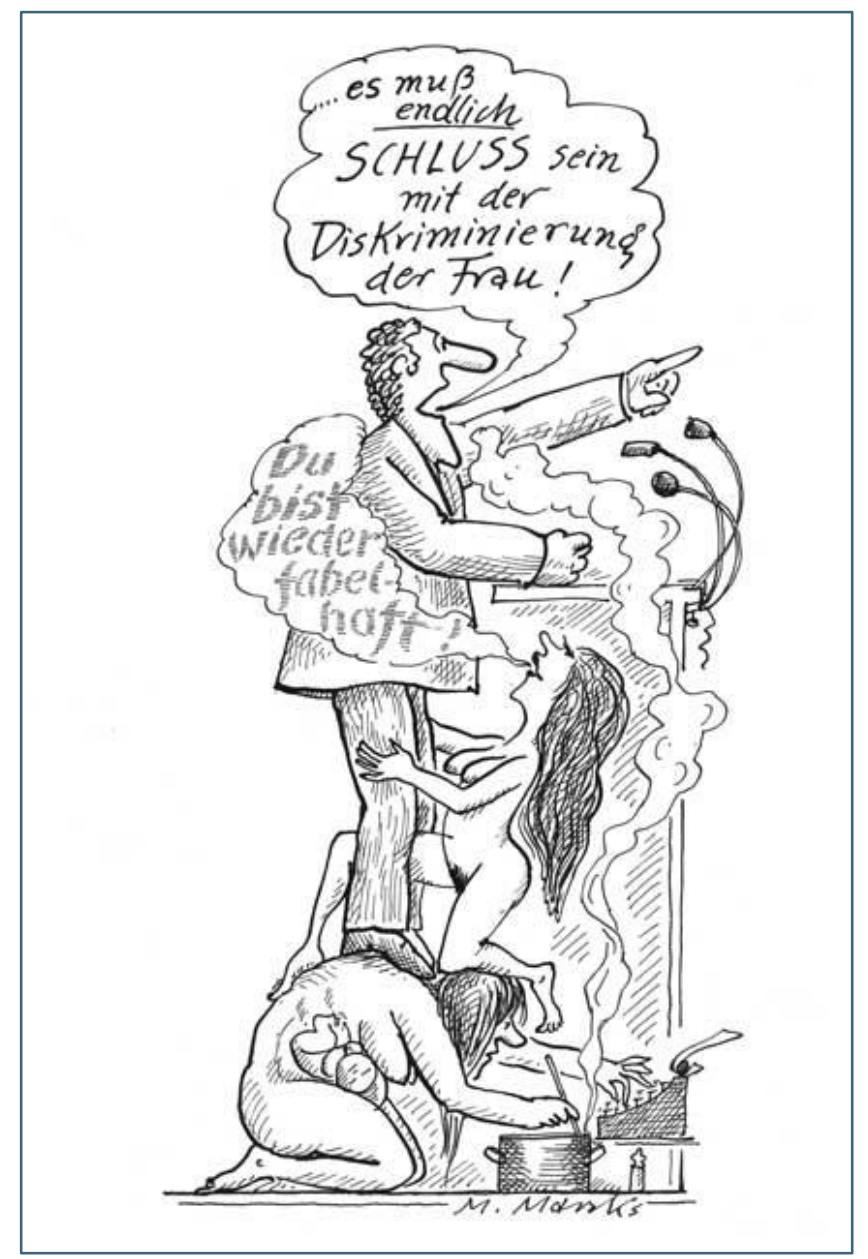

Fonte: Stern, [Deutschland], Hamburg, 24 jul. 1981. Disponível em: [http://mariemarcks.de/galerie/galerie-detail/frau\%20und\%20mann/177/es-muss-endlich-schluss-sein-mitder-diskriminierung-der-frau]. Acesso em: 06 jan. 2020. 
Na imagem acima (Figura 03), também estruturada em forma de pirâmide (Figura 03a), a lógica da sujeição feminina é mais uma vez colocada em evidência nos mesmos moldes: parece não haver uma perspectiva de mudança e nem uma ação feminina que se volte à alteração do quadro. A mulher ajoelhada na base da pirâmide, nua e com um bebê junto ao ventre, não parece ter sequer tempo ou energia para pensar em alterar sua situação. Enquanto cuida do bebê, ela datilografa algo com a mão esquerda (um novo discurso?) e, com a direita, prepara a comida que alimentará o homem (o curso da fumaça que sai da panela e segue até a boca do homem que discursa demarca seu propósito). Há, entretanto, aqui, uma potencialidade de interferência na realidade que surge da ação dessa mulher no processo de anotação e de produção dos discursos do homem. Essa potencialidade, nessa lógica, reside na capacidade masculina de atuação na esfera pública, ou seja, a ação feminina se mostra indireta, e sua interferência depende, em última medida, da capacidade e da amplitude alcançada pela atuação do homem. A mulher, nesse esquema, se retrai, mantém-se resignada a seu espaço, determinado, de forma esquemática, na parte inferior da divisão dessa estrutura piramidal (Figura 03b).
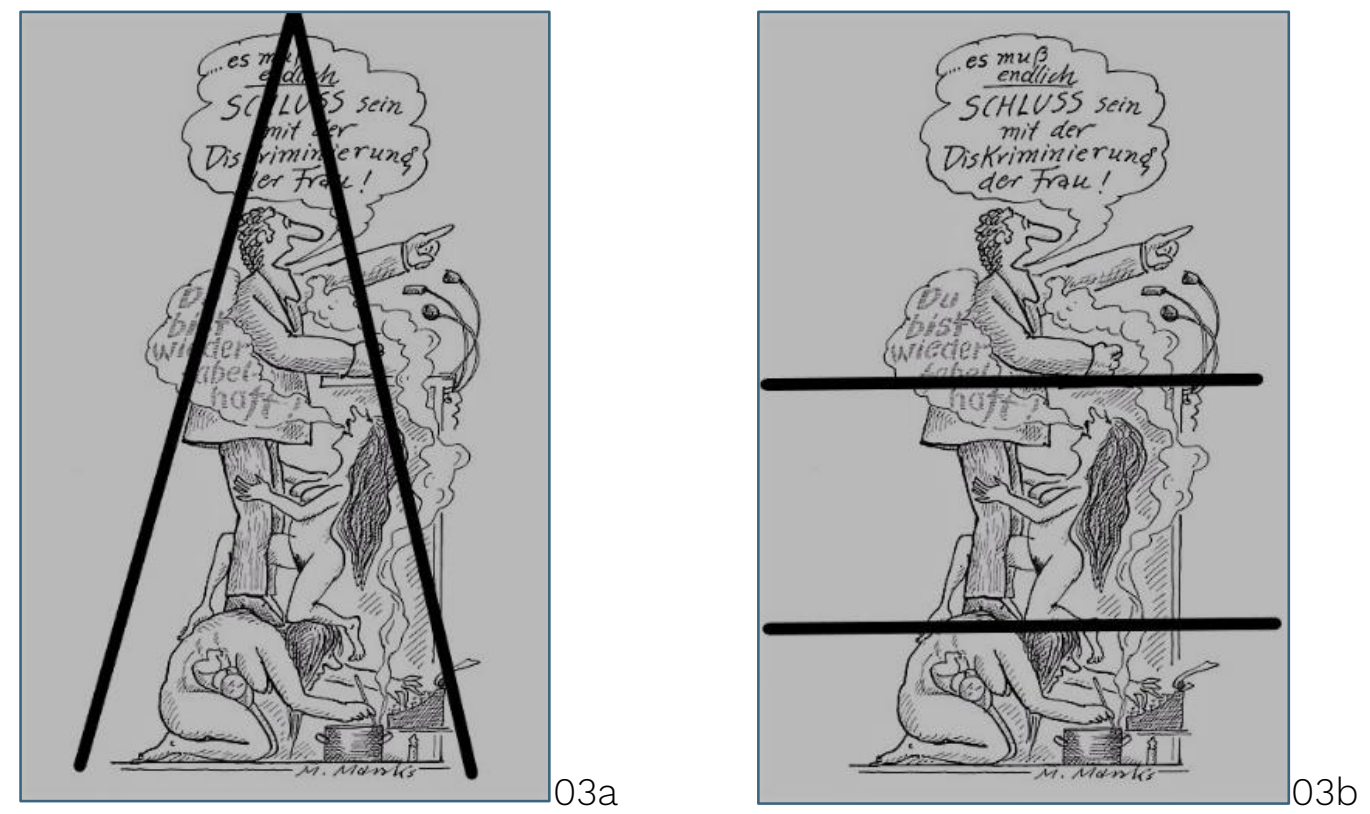

A continuidade da divisão dessa estrutura relega ainda a mulher a uma outra esfera, a da sexualidade. Fica clara a performatividade que é encenada aqui: a mulher, ajoelhada frente ao homem (e sobre a mulher "doméstica"), simula ato 
sexual. Mais do que isso, a fala da mulher nesse campo da imagem (Du bist wieder fabelhaft / Você está novamente fabuloso) evidencia que a felação simulada é, na verdade, combustível à autoestima do orador. Revela-se aqui um papel duplo da mulher (ou das mulheres, uma vez que não fica claro se os papéis são desempenhados por uma única e mesma mulher ou por duas mulheres diferentes): ela não apenas é a responsável pela preparação e organização da vida privada e pública do homem, mas é também a responsável, com sua sexualidade, pelo impulso para a vida pública, por seu encorajamento, autoestima, coragem e, claro, pela boa manutenção do ego do mesmo. São dois espaços ocupados por mulheres nessa estrutura, ambos voltados ao campo do privado. No desenho de Marcks, evidencia-se uma problematização da divisão "tradicional" do público e privado enquanto espaços masculino e feminino "por natureza", além da consciência da posição da mulher no campo "público e masculino" nos trabalhos invisíveis. A composição da imagem, com a sujeição completa da mulher e sua sexualização em benefício do homem, promove um enquadramento político emocional que fala diretamente às mulheres, evidenciando-se a partilha do sensivel que Rancière aponta fundada "sobre a partilha de espaços (e visualidades), de tempos e das formas de ação que determina a maneira mesma na qual um comum se dá à participação e no qual uns e outros tomam parte na partilha." (RANCIÈRE, 2000, p. 12).

Mas apesar de toda a centralidade que tem a mulher na condução da ação masculina, no plano público, naquele plano do político que se dá à visualidade, é apenas o homem que surge, o que fica representado perfeitamente na divisão superior da Fig. 08. O corte que é proposto na imagem concentra em si os microfones (capacidade de fala), o rosto do homem (visualidade) e o braço gesticulante do mesmo (potencialidade de ação). Em outras palavras, o reconhecimento expresso na charge pelo discurso que o elemento masculino profere ("é preciso acabar de uma vez por todas com a discriminação da mulher") é todo direcionado a ele mesmo.

A temática central da imagem, claro, parece ser a hipocrisia do discursador, que defende a liberação feminina mas, em sua própria vida privada (em sua base) mantém um sistema de subjugação feminina a seu favor. Se Marcks desenhasse no Brasil de hoje, talvez o título do cartum fosse "O Esquerdo-macho", 
denominação comum no vocabulário feminista atual para o homem de esquerda que se utiliza do discurso feminista para angariar admiradores e admiradoras e que, na vida privada, mantém comportamentos caracterizados como machistas. Mas, apesar de não ser brasileira e desenhar no início da década de 1980, Marie Marcks denuncia a existência de "esquerdo-machos" na Alemanha, na revista com a maior circulação da Alemanha de então (a Stern contava com a venda de cerca de 1,5 milhão de exemplares por semana (SCHRÖDER, 2016).). Em Marcks, o foco não é o campo público do feminismo, o das lutas das ruas, dos manifestos ou das organizações. Para ela, o ponto crucial era a conscientização das mulheres em suas vidas privadas, em seu cotidiano. É a mulher, e não a militante, que é seu público-alvo.

\section{Considerações finais}

Se não é a militante que é seu público-alvo, fica clara a opção de Marcks de promover essa ação visual-educacional, por assim dizer. Nessa ação reside também sua justificativa de não participar de organizações feministas de forma oficial: ela não faz política, mas age no campo do político de forma direta e incisiva, buscando falar justamente àquelas mulheres (e homens) que não têm contato direto com a militância feminista ou acesso a outras formas de materiais que joguem luz sobre a situação feminina na sociedade alemã. Mais do que isso, a própria Marcks afirmava que sua ação feminista não vinha do feminismo, seus princípios ou sua teoria. Em entrevista à Südwestrundfunk, ela explicava sua posição em relação à questão:

Jutta Limbach (jurista e professora da Freie Universität Berlin) disse uma vez que eu era uma feminista de primeira hora. Eu nunca realmente me entendi dessa forma. Se você tem dois filhos e três filhas, é claro que os dois filhos vêem o mundo com seus olhos masculinos, é algo completamente diferente. E as mulheres que têm filhos pensam e refletem muito mais sobre isso. (MARCKS, 2012)

O feminismo de Marcks vinha de uma posição social, de sua condição de "mãe de meninos", de sua lida com a visão masculina no cotidiano e sua percepção do diferente. Sua exposição e sua posição no debate público 
extrapolam essa posição e a colocam como uma formadora de opiniões, levando sua experiência de "mãe de meninos" e, principalmente, suas reflexões acerca dessa condição a uma audiência ampla. Ligada a uma gama de veículos de alcance nacional, ela age na formação de um espaço de experiências e de sentido ligados à sua obra que, virtualmente, abrangia o país inteiro. Nesse processo, a temática do cotidiano familiar se mostrava como um de seus campos mais férteis, rendendo à chargista boa parte de suas reflexões sobre a mulher na contemporaneidade.

Fig. 04: MARCKS, Marie. Du hast es já nicht anders gewollt! (Você não iria querer que fosse diferente!). 1980.

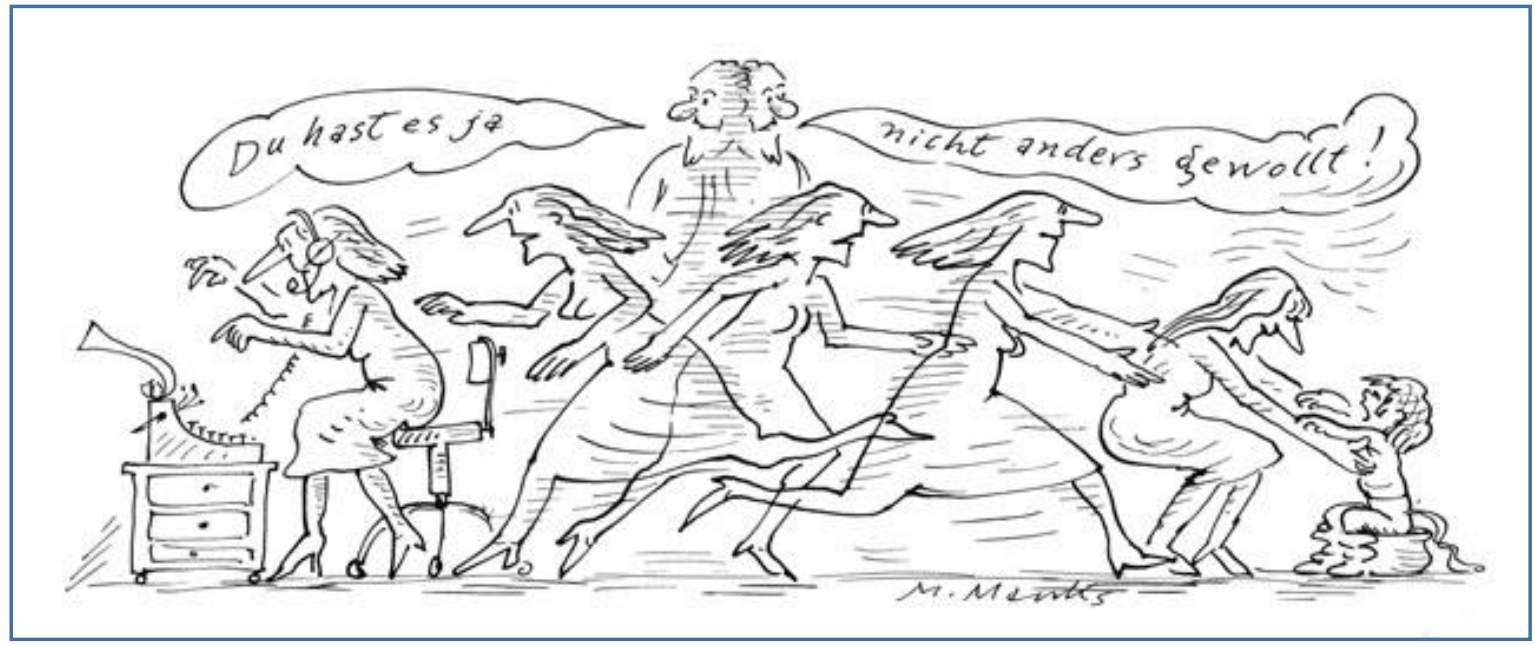

Fonte: Brigitte, Hamburg, 1980. Disponível em: http://marie-marcks.de/galerie/galeriedetail/frau/649/du-hast-es-ja-nicht-anders-gewollt. Acesso em: 08 jan. 2020.

Pode-se afirmar que o resultado é uma crônica das mulheres alemãs na sociedade industrial contemporânea, conjugada em saberes ateóricos absorvidos pela chargista em sua lida diária. Isso não diminui, por óbvio, a qualidade e a importância de seu trabalho. Mas é uma indicação da razão de seus desenhos apontarem para uma passividade feminina nessa composição machista do mundo: Marcks não se preocupava em chamar à ação as mulheres alemãs, mas sim em conscientizá-las de sua conformação. Se por vezes pode parecer que em suas representações a emancipação política e social das mulheres depende, primariamente, da ação dos homens, isso se deve a sua própria condição histórica, seu contexto de produção e de formação. Suas charges e cartuns 
oscilam entre o chiste direto e "familiar" e o cinismo, a ironia fina da contraposição entre a imagem e o texto (normalmente vinculado ao personagem masculino). Como na imagem acima (Figura 04), na qual o homem observa a mulher se desdobrar entre o trabalho e o cuidado de seu filho e afirma "você não iria querer que fosse diferente". Datada de 1980, a imagem mostra uma questão presente em todo o século XX (e XXI), mas muito particularmente cara às mulheres daquela geração: a conciliação entre a carreira e a vida privada, a constituição de uma família e a vida profissional (algo que Marie Marcks sempre vivenciou, desde os anos 1950). Nessa estratégia narrativa e visual surge, na verdade, uma situação potencialmente disruptiva, possibilitada pela conscientização.

Na questão gráfica, ainda outro elemento precisa ser levantado: o corpo feminino. Em suas representações, a conformação das mulheres é visualmente perceptível. Evidencia-se uma dicotomia entre corpos conformados, com uma performatividade fechada, pré-concebida e dada, e o corpo em si, livre, marcado por sua imprevisibilidade. Os corpos femininos em Marcks, em sua conformação e dando-se à visibilidade, estão a um passo da ruptura; e esse passo necessário é a conscientização de seu espaço e de sua potência, da possibilidade de um mundo não apenas masculino, mas que também seja - e opere pelas regras do - feminino. É nessa característica da conscientização, que na verdade é a essência das imagens acerca do feminino de Marcks, que sua obra pode ser caracterizada plenamente como feminista.

\section{Referências}

ANDERSON, Benedict. Imagined communities. London: Verso, 2006.

ANSART, Pierre. Ideologia, conflito e poder. Rio de Janeiro: Zahar, 1978.

ARENDT, Hannah. Origens do totalitarismo. São Paulo: Cia das Letras, 1999.

ARENDT, Hannah. A condição humana. Rio de Janeiro: Forense Universitária, 2005. 
ARENDT, Hannah. A vida do espírito. Rio de Janeiro: Civilização Brasileira, 2012.

BERGSON, Henri. O riso. São Paulo: Martins Fontes, 2001.

BOHNSACK, Ralf. A Interpretação de imagens e o método documentário.

Sociologias, Porto Alegre, n. 18, v. 9, p. 286-311, jun./dez. 2007.

BOHNSACK, Ralf. Qualitative bild- und videointerpretation. Opladen: Budrich, 2009.

EICKHOFF, Katharina. Ich war immer eine politische karikaturistin. SWR2 Kulturgespräch, [S.l.], 09 ago. 2012. Disponivel em:

https://www.swr.de/swr2/kultur-info/marie-marcks-zum-90-geburtstag/$/ \mathrm{id}=9597116 / \mathrm{did}=10160026 / \mathrm{nid}=9597116 /$ 1q2zbz6/index.html. Acesso em: 30 dez . 2019.

OLYMPIA 1936 war mein größtes Abenteuer. Frankfurter Allgemeine Zeitung. Frankfurt am Main, 13 set. 2013. Disponível em:

https://www.faz.net/aktuell/feuilleton/bilder-und-zeiten/fragen-an-zweigenerationen-olympia-1936-war-mein-groesstes-abenteuer-12572588.html. Acesso em: 04 jan. 2020. Feuilleton. Fragen an zwei Generationen.

FREVERT, Ute. Women in german history. Oxford: Berg, 1997.

GREER, Germaine. A mulher eunuco. Rio de Janeiro: Artenova, 1971.

KLAUS, Elisabeth; WISCHERMANN, Ulla. Journalistinnen: eine geschichte in biographien und texten (1848-1990). Wien: LIT, 2013.

LIEBEL, Vinicius. A análise de charges segundo o método documentário. In: WELLER, Wivian; PFAFF, Nicolle (org.). Metodologias da pesquisa qualitativa em educação. Petrópolis: Vozes, 2010. p. 182-196.

LIEBEL, Vinicius. Entre Sentidos e Interpretações: apontamentos sobre a análise documentária de imagens. ETD - Educação Temática Digital, v. 12, p. 172-189, 2011.

LIEBEL, Vinicius. O historiador e o trato com as fontes pictóricas. Topoi, Rio de Janeiro, v. 17, n. 33, p. 372-398, 2016.

LOWER, Wendy. As mulheres do nazismo. Rio de Janeiro: Rocco, 2014.

MARCKS, Marie. Ich war immer eine politische karikaturistin: ausstellung im Frankfurter Caricatura-Museum über ihr Lebenswerk eröffnet. [Entrevista cedida a] Katharina Eickhoff. SWR2 Kultur, Baden-Baden, 09 ago. 2012. 
Disponível em: https://www.swr.de/swr2/kultur-info/marie-marcks-zum-90geburtstag $/ / \mathrm{id}=9597116 / \mathrm{did}=10160026 / \mathrm{nid}=9597116 / 1 \mathrm{q} 2 \mathrm{zbz6} / \mathrm{index} \cdot \mathrm{html}$. Acesso em: 09 jan. 2020.

MOUFFE, Chantall. Agonistique: penser politiquement le monde. Paris: Ed. Des Beaux-Arts, 2014.

MOUFFE, Chantall. Sobre o político. São Paulo: Martins Fontes, 2016.

MUCHEMBLED, Robert. Insoumises: - une autre histoire des françaises. Paris: Autrement, 2013.

PRZYBORSKI, Aglaja. Bildkommunikation: qualitative bild- und medienforschung. Berlin: De Gruyter, 2017.

RANCIĖRE, Jacques. Le partage du sensible. Paris: La Fabrique, 2000.

SCHMITT, Carl. O conceito do político / teoria do partisan. Belo Horizonte: Del Rey, 2008.

SCHRÖDER, Jens. Historische analyse: Spiegel und Stern im 66-JahreAuflagentrend. Meedia, München, 12 fev. 2016. Disponível em:

https://meedia.de/2016/02/12/historische-analyse-spiegel-und-stern-im-66jahre-auflagentrend-rekorde-mit-kennedy-und-dem-irak-krieg/. Acesso em: 08 jan. 2020.

SJÖHOLM, Cecilia. Doing aesthetics with Hannah Arendt. New York: Columbia Univ. Press, 2015.

STATEN, Henry. Wittgenstein and Derrida. Lincoln and London: Univ. of Nebraska Press, 1984. 